\title{
Dominant-negative soluble PDGF- $\beta$ receptor inhibits hepatic stellate cell activation and attenuates liver fibrosis
}

\author{
Erawan Borkham-Kamphorst, Jens Herrmann, Doris Stoll, Jens Treptau, Axel M Gressner \\ and Ralf Weiskirchen
}

Institute of Clinical Chemistry and Pathobiochemistry, RWTH-University Hospital, Aachen, Germany

\begin{abstract}
Hepatic fibrogenesis is a consequence of hepatic stellate cells that become activated and transdifferentiate into a myofibroblastic phenotype with the ability to proliferate and synthesize large quantities of extracellular matrix components. In this process, platelet-derived growth factor (PDGF) is the most potent stimulus for hepatic stellate cell proliferation and migration, and is overexpressed during active hepatic fibrogenesis. This cytokine binds to the PDGF receptor type $\beta$, activates Ras and sequentially propagates the stimulatory signal sequentially via phosphorylation of Raf-1, MEK and the extracellular-signal regulated kinases ERK1/ERK2. Hepatic injury is associated with both increased autocrine PDGF signaling and upregulation of PDGF receptor. In this study, we report that a dominant-negative soluble PDGF- $\beta$ receptor consisting of a chimeric IgG containing the extracellular portion of the PDGF receptor type $\beta$ blocks HSC activation and attenuates fibrogenesis induced by ligation of the common bile duct in rats. In culture-activated hepatic stellate cells, the soluble receptor blocks phosphorylation of endogenous PDGF receptor, phosphorylation of the ERK1/EKR2 signal and reduces proliferative activities of HSC. In vivo, both the delivery of the purified soluble PDGF antagonist and the administration of adenoviruses expressing the artificial transgene were able to reduce significantly the expression of collagen and $\alpha$-smooth muscle actin. Our results demonstrate that PDGF plays a critical role in the progression and initiation of experimental liver fibrogenesis, and suggest that early antiPDGF intervention should have a therapeutical impact on the treatment of liver fibrogenesis.
\end{abstract}

Laboratory Investigation (2004) 84, 766-777, advance online publication, 26 April 2004; doi:10.1038/labinvest.3700094

Keywords: bile duct ligature; TGF- $\beta 1$; myofibroblast; hepatic stellate cell; PDGF; liver; fibrosis

Hepatic fibrosis is a proliferative disease that may be initiated by a variety of factors including chronic viral hepatitis, alcoholic abuse, drug-induced lesions, heritable metabolic alterations, or exceptional functional disorders. Following liver injury of any etiology, hepatic stellate cells (HSC) become activated and transdifferentiate into proliferative, fibrogenic, and contractile myofibroblasts (MFB). The perpetuation of the activated phenotype involves key phenotypic responses mediated by increased cytokine effects and remodeling of extracelluar matrix (ECM). ${ }^{1,2}$ Enhanced cytokine responses occur through multiple mechanisms; among these, increased expression of cell membrane receptors and enhanced signaling are essential. In particular,

Correspondence: Dr R Weiskirchen, Institute of Clinical Chemistry and Pathobiochemistry, RWTH-University Hospital, D-52074 Aachen, Germany.

E-mail: rweiskirchen@ukaachen.de

Received 12 December 2003; revised 12 February 2004; accepted 14 February 2004; published online 26 April 2004 receptor tyrosine kinases, for example, receptors for platelet-derived growth factor (PDGF), which mediate many of the stellate cell's responses to cytokines, are broadly upregulated during liver injury. ${ }^{3}$ PDGFs form a family of dimeric isoforms inducing growth stimulation, chemotaxis, cell shape changes, and intracellular signaling in HSC from mouse, rat, or humans. ${ }^{3}$ The PDGF receptor type $\alpha$ (PDGFR $\alpha$ ) is constitutively expressed in quiescent HSC, whereas PDGF receptor type $\beta$ (PDGFR $\beta$ ) is acquired as the cells undergo myofibroblastic phenotypic changes. ${ }^{4}$ Moreover, in liver tissue obtained from patients with chronic liver diseases, the expression of PDGF and its receptor subunits appears closely correlated to the extent of necroinflammation and fibrosis. ${ }^{5}$ The cellular effects of PDGF isoforms are exerted through binding to two structurally related tyrosine kinase receptors. Ligand binding induces receptor dimerization and phosphorylation of tyrosine residues within the cytoplasmic domain, enabling a number of srchomology 2 (SH2) or phosphotyrosine-binding 
(PTB) domains to bind to the phosphorylated receptors. This induces recruitment and activation of receptor-associated proteins following sequential activation of Ras, Raf-1, MEK and in turn the extracellular-signal regulated kinases ERK1 and ERK2 (also referred to as p44 and p42), thereby initiating various signaling pathways. ${ }^{6-8}$ Subsequently, ERKs translocate into the nucleus and phosphorylate several transcription factors triggering a proliferative response. ${ }^{9}$ In both cultured HSC and HSC of injured liver, there is a strong activation of the ERK pathway. ${ }^{10,11}$ Increasing evidence indicates that the enhanced activity of PDGFR plays a pivotal role in liver fibrosis. Importantly, codistribution of PDGF with cells expressing its receptors has been clearly demonstrated after both acute and chronic liver tissue damage,,$^{5,12}$ thus confirming an active role of this growth factor in the liver tissue repair process and in the development of hepatic fibrosis. Therefore, targeting the PDGF system by drugs that inhibit the tyrosine kinase receptor, or its intracellular signal transduction pathway, is attractive for therapeutic intervention in hepatic fibrosis. Some of these components were shown to prevent cellular activation and are beneficial in experimental models of liver fibrosis. ${ }^{10,13-15}$ However, most of these agents will likely not be suitable for therapeutic applications in humans, because most of the main signaling pathways involved in PDGF-induced biological effects are common to other growth factors possibly acting with positive effects on other cell types within the same tissue. ${ }^{3}$ Therefore, direct scavenging of PDGF or application of methods allowing targeting to HSC undergoing cellular activation and subsequent transdifferentiation would offer a strategy for the treatment of fibrotic liver diseases. Inspired by the overwhelming literature describing the highly beneficial impact of local or systemic expression of a dominant-negative TGF- $\beta$ receptor (T $\beta$ RII) resulting in the reduction of liver fibrogenesis, improved liver function, and inhibition of cellular activation, ${ }^{16-18}$ we examined the effects of a dominant-negative soluble PDGFR $\beta$ (sPDGFR $\beta$ ) on hepatic fibrogenesis in culture-activated HSC and in a biliary obstruction model induced by ligature of the common bile duct (BD) in rats.

\section{Materials and methods}

\section{Cell Isolation and Culture}

HSC were isolated from male Sprague-Dawley rats by the pronase-collagenase method followed by a density centrifugation on a Nycodenz gradient and cultured as described before. ${ }^{19,20}$

\section{Construction of Ad5-CMV-EGFP, Ad5-CMV-sT/ $\beta$ RII, and Ad5-CMV-sPDGFR $\beta$}

The construction of the recombinant replicationdeficient reporter Ad5-CMV-EGFP expressing the enhanced green fluorescent protein (EGFP) was described previously. ${ }^{21}$ For cloning of $\mathrm{p} \Delta \mathrm{E} 1 \mathrm{sp} 1 \mathrm{~A}$ CMV-sT $\beta$ RII, the NcoI fragment of the plasmid pIghT $\beta$ RII ${ }^{22}$ was blunted and cloned into the EcoRI site of $\mathrm{p} \Delta \mathrm{E} 1 \mathrm{sp} 1 \mathrm{~A} .{ }^{23}$ The extracellular domain (ECD) of rat PDGFR $\beta$ was isolated by RT-PCR from total rat MFB RNA using primers $5^{\prime}$-d(CAT GGG GCT TCC AGG AGT GAT)- $3^{\prime}$ and $5^{\prime}$-d(GGG CAA GGA ATG TGG GAC CAC)-3', corresponding to nt138-nt158 or complementary to nt1702-nt1722 of murine PDGFR $\beta$ mRNA (Access. No. NM_008809). The resulting cDNA fragment was cloned into pGEM-T Easy (Promega, Mannheim, Germany) generating vector pGEM-rPDGFR $\beta$, followed by a second amplification using primer $5^{\prime}$-d(GAA TTC GGA CAC CAT GGG GCT TCC AGG AGT GAT)-3' ${ }^{\prime}$ and $5^{\prime}$-d(GGA TCC ACT TAC CTG TCA AGG AAT GTG GGA CCA)-3' introducing novel restriction sites for EcoRI and BamHI (underlined) and a downstream $3^{\prime}$-splice donor site (in bold). Subsequently, the ECD of PDGFR $\beta$ was incorporated into vector pIg harboring the Fc region of human IgG1, a CMV promoter, and SV40-polyadenylation signal. ${ }^{22}$ Then, the $\sim 4.2 \mathrm{kbp}$-fragment containing the PDGFR $\beta: \mathrm{FC}_{\mathrm{C}}$ fusion (sPDGFR $\beta$ ), along with the CMV promoter and SV40-polyadenylation signal was transferred into the EcoRI and HindIII sites of adenoviral shuttle vector $\mathrm{p} \Delta \mathrm{E} 1 \mathrm{sp} 1 \mathrm{~A}$. The integrity of all cloning boundaries was verified by sequencing, and the integration of the expression cassette from vector $\mathrm{p} \triangle \mathrm{E} 1 \mathrm{sp} 1 \mathrm{~A}-\mathrm{CMV}-\mathrm{PDGFR} \beta$ into the adenoviral backbone vector $\mathrm{pJM} 17^{24}$ was achieved by in vitro homologous recombination as described. ${ }^{21}$

\section{RNA Isolation and Northern Blot Analysis}

Isolation, gel electrophoresis, and Northern blot analysis of RNA was carried out as described previously. ${ }^{20,25}$ Hybridization probes were the 975bp EcoRI fragment of pGEM-rCol $\alpha 1$ (I) (a kind gift from $\mathrm{K}$ Knoch), and the $\sim 1.6-\mathrm{kbp}$ fragment of pGEM-rPDGFR $\beta$, respectively. For internal standardization, the blots were rehybridized with a cDNA specific for glyceraldehyde-3-phosphate dehydrogenase $(G A P D H)$.

\section{Polymerase Chain Reaction (PCR) for SPDGFR $\beta$ Expression Analysis}

Total RNA ( $2 \mu \mathrm{g})$ isolated from liver samples was reverse transcribed in $20 \mu \mathrm{l}$ using Superscript II Reverse Transcriptase (Invitrogen, Karlsruhe, Germany) and random hexamer primers according to the manufacturer's instructions. Aliquots $(2 \mu \mathrm{l})$ of the first strand cDNA samples were subjected to standard PCR using primer $5^{\prime}$-d(GCC TGC GTC ACG TGG ACC A)-3', corresponding to the ECD of rat PDGFR $\beta$ (nt1383-1401; Acc. No. Z14119), and primer 5'-d(GGA AGA GGA AGA CTG ACG GT)-3', specific for the Fc region of human IgG1. To verify 
the integrity of each cDNA, a 251-bp fragment of $G A P D H$ was amplified. Primers, according to Access. No. M32599, were $5^{\prime}$-d(TCG TGG ATC TGA CGT GCC GCC TG)- $3^{\prime}$ and $5^{\prime}$-d(CAC CAC CCT GTT GCT GTA GCC GTA T)-3’.

\section{SDS-PAGE and Immunoblotting}

Whole cell or liver extracts were prepared as described before. ${ }^{26-28}$ Equal amounts of proteins were resolved in NuPAGE ${ }^{\mathrm{TM}}$ Tris-Glycine gels (Novex, Groningen, The Netherlands) and electroblotted onto a Protran membrane (Schleicher \& Schuell, Dassel, Germany) according to standard procedures. The primary antibodies used were: $\alpha$ SMA (clone asm-1 obtained from Roche, Mannheim, Germany or from Cymbos Biotech Ltd., Chandlers Ford, UK), PDGFR $\beta$ (sc-432, Santa Cruz Biotech, Santa Cruz, CA, USA), p-PDGFR $\beta$ (sc-12907, Santa Cruz), PDGFR $\beta$ (ECD) (Ab-1\#PC17, Oncogene, San Diego, CA, USA), p44/p42 (\#9102, Cell Signaling Technology, Inc., New England Biolabs $\mathrm{GmbH}$, Frankfurt, Germany), and phospho-p44/42 (Thr202/ Tyr204) (\#9101, Cell Signaling Technology). Primary antibodies were visualized using horseradish peroxidase-conjugated anti-mouse IgG or anti-rabbit IgG (Santa Cruz) and the supersignal chemiluminescent substrate (Pierce, Rockford, IL, USA).

\section{ELISA for SPDGFR $\beta$}

For quantification of sPDGFR $\beta$ in rat serum, 96-well plates (C8 Maxisorp 445101, Nunc, Wiesbaden, Germany) were coated overnight at $4^{\circ} \mathrm{C}$ in $50 \mathrm{mM}$ $\mathrm{NaHCO}_{3}(\mathrm{pH}$ 9.1) containing $5 \mu \mathrm{g} / \mathrm{ml}$ rabbit antihuman IgG specific for the $\mathrm{C}_{\mathrm{H}} 2$ domain (A 0089, DAKO, Hamburg, Germany). The plates were washed three times $(0.05 \%$ Tween $20,154 \mathrm{mM}$ $\mathrm{NaCl}$ ) and blocked with $200 \mu \mathrm{l} 0.5 \%$ BSA (RIA grade, Sigma, Taufkirchen, Germany) in blocking buffer $(50 \mathrm{mM}$ Tris $\mathrm{pH} 7.7,150 \mathrm{mM} \mathrm{NaCl})$ at $4^{\circ} \mathrm{C}$ overnight. Upon washing, $100 \mu \mathrm{l}$ diluted rat serum was applied to duplicate wells after being diluted two times with assay buffer $(0.05 \%$ Tween 20 in blocking buffer). A standard curve was set using $100 \mu \mathrm{l}$ of the purified sPDGFR $\beta(0-100 \mathrm{ng} / \mathrm{ml})$ in $50 \%$ pooled-rat serum. The plates were incubated for $2 \mathrm{~h}$ at RT followed by washing and application of $100 \mu \mathrm{l}$ of $0.5-1 \mu \mathrm{g} / \mathrm{ml}$ polyclonal goat anti-mouse PDGFR $\beta$ antibody (AF1042, R\&D Systems, Wiesbaden, Germany) for $1 \mathrm{~h}$ at RT. After the next washing, $100 \mu \mathrm{l}$ of 1:2000 diluted polyclonal horseradish peroxidase-conjugated donkey antigoat IgG antibody (sc-2056, Santa Cruz) was added, and further incubated for $1 \mathrm{~h}$ at RT. BM blue POD substrate solution containing $3,3^{\prime}-5,5^{\prime}$-tetramethylbenzidine (Roche) was applied after washing and plates were incubated at RT. The reaction was interrupted after 10-30 min with $50 \mu \mathrm{l}$ of $1 \mathrm{M} \mathrm{H}_{2} \mathrm{SO}_{4}$ and absorbance was measured in a Victor Multilabor microplate reader (EG\&G Wallac, Turku, Finland) at $450 \mathrm{~nm}$ against a reference wavelength of $690 \mathrm{~nm}$.

\section{Expression, Purification, and Sequencing of Soluble Receptors}

COS-7 cells were infected with Ad5-CMV-sT $\beta$ RII or Ad5-CMV-sPDGF $\beta$ in DMEM supplemented with $10 \%$ fetal calf serum (FCS), $2 \mathrm{mM}$ L-glutamine, $100 \mathrm{IU} / \mathrm{ml}$ penicillin, and $100 \mu \mathrm{g} / \mathrm{ml}$ streptomycin. After 1 day, the medium was changed (0.5\% FCS) and cells were cultured for additional $48 \mathrm{~h}$. Thereafter, the supernatants were taken, cleared by a highspeed centrifugation, and proteins (sT $\beta$ RII or sPDGFR $\beta$ ) were isolated on a Hi Trap G column (Amersham Pharmacia Biotech, Freiburg, Germany) according to the instructions of the manufacturer. For protein sequencing purified samples were dialyzed extensively against deionized water and five $(\operatorname{sPDGFR} \beta)$ or six (sT $\beta$ RII) aminoterminal aminoacids were sequenced by Edman degradation at TOPLAB (Martinsried, Germany).

\section{Adenoviral Expression Technology}

Purification, infection of cultured liver cells, and administration of adenoviruses to animals were performed as described previously. ${ }^{21,26-28}$

\section{Proliferation Assay}

HSC were cultured in DMEM containing 10\% FCS. On the 2nd day after seeding the serum content was reduced to $0.5 \%$ FCS for $24 \mathrm{~h}$ and cells were stimulated with $20 \mathrm{ng} / \mathrm{ml}$ PDGF-BB (R\&D) and treated with indicated concentrations of purified sPDGFR $\beta$. After a $24 \mathrm{~h}$ incubation period, cells were then exposed to $75 \mathrm{kBq} / \mathrm{ml}\left[6{ }^{3} \mathrm{H}\right]$-thymidine (NEN Life Science Products, Dreieich, Germany) for a $24 \mathrm{~h}$ labeling period. Radioactivity incorporated into DNA was measured as described before. ${ }^{29}$

\section{Experimental In Vivo Model of Liver Fibrogenesis}

Male Sprague-Dawley rats were infected with recombinant adenoviruses $\left(2 \times 10^{10} \mathrm{pfu} / \mathrm{animal}\right)$, or normal saline solution via the tail vein. After 2 days the common $\mathrm{BD}$ was double ligated and excised under halothane anesthesia. Rats were killed after 9 days, and pieces of the livers were fixed in $4 \%$ paraformaldehyde for histological examination or were frozen immediately in liquid nitrogen and stored at $-80^{\circ} \mathrm{C}$ for protein and RNA isolation. The study as presented was approved by the local committee for care and use of laboratory animals, and was performed according to strict governmental and international guidelines on animal experimentation. For application of purified soluble receptor proteins (sT $\beta$ RII, sPDGFR $\beta$ ), $25 \mu \mathrm{g} /$ animal $(0.1 \mathrm{mg} / \mathrm{kg}$ 
body weight) was administered intravenously upon bile duct ligature (BDL) according to established protocols. $^{30}$ Injections into the peritoneum were repeated twice a week until the animals were killed 14 days after surgery.

\section{Histological Examination of Liver Tissues}

Sirius Red staining was performed as described previously. ${ }^{31}$ Briefly, liver sections were deparaffinized and the slides were incubated for $1 \mathrm{~h}$ in a solution of saturated picric acid containing $0.1 \%$ Sirius Red 80. Stained slides were then incubated in $0.01 \mathrm{~N} \mathrm{HCl}$ for $2 \mathrm{~min}$ and washed in running distilled water, dehydrated, mounted, and examined by light microscopy.

\section{Immunohistochemistry}

Tissue sections $(1.5 \mu \mathrm{m})$ were treated with xylene, rehydrated with decreasing graded ethanol, and blocked against endogenous peroxidase using $3 \%$ $\mathrm{H}_{2} \mathrm{O}_{2}$. For $\alpha$-SMA staining, the slides were treated with a monoclonal anti $\alpha$-SMA (asm-1, Roche) followed by incubation with a biotinylated antimouse secondary antibody (BA-9200, Vector Laboratories, Burlingame, CA, USA). Thereafter, the secondary antibodies were complexed with an avidin-conjugated peroxidase (Vectastain ABC-Elite reagent, Vector Laboratories) and peroxidase activity was detected with diaminobenzidine (DAKO). For better documentation the tissue sections were briefly counterstained with methyl green.

\section{Statistics}

Results are presented as the mean of three independent experiments ( \pm s.d.). Statistical analysis was performed with an unpaired Student's $t$-test and differences were considered as significant ${ }^{*}$ ) or highly significant $\left({ }^{* *}\right)$ at $P<0.05$ or $<0.01$, respectively.

\section{Results}

\section{Cloning, Expression and Purification of sPDGFR $\beta$}

The spontaneous activation of HSC on plastic and the induction of fibrogenesis by ligature of the common BD are established model systems for liver fibrosis in rat. In general, cultured HSC and MFB are nearly refractory to gene transfer by physical methods but vector systems based on adenoviruses (Ad) are suitable for delivery of transgenes into this hepatic subpopulation. ${ }^{21}$ We generated adenovirus serotype 5 (Ad5) for constitutive expression of a chimeric cDNA, termed sPDGFR $\beta$, encoding the ECD of the PDGF receptor type $\beta$ fused to the IgG$\mathrm{FC}_{\mathrm{C}}$ domain of human immunoglobulin. In this construct, both domains are separated by an intron of $379 \mathrm{bp}$ in size (Figure 1a). In the translated protein the ECD of PDGFR $\beta$ is linked to the Fc domain via a two-amino-acid spacer. A similar construct harboring the ECD of the TGF- $\beta$ receptor type II (T $\beta$ RII) fused to the Fc domain was cloned previously. ${ }^{32}$ The expression of the chimeric sPDGFR $\beta$ was assessed by Northern blot and Western blot. In COS-7 cells, Ad5-CMV-sPDGFR $\beta$ infection resulted in a viral dose-dependent synthesis of two mRNAs approximately 4000 and $3600 \mathrm{nt}$ in length, which were compatible with the expected sizes for the mature mRNA of the PDGFR $\beta$-Fc fusion and its progenitor RNA harboring an intron of $379 \mathrm{nt}$ (Figure 1b). The synthesis of the chimeric protein product was demonstrated in Western blot using a polyclonal antibody directed against the ECD of PDGFR $\beta$ (Figure 1c). To confirm that the synthesized protein is bivalent and has the proposed antibody-like structure, sPDGFR $\beta$ was purified from culture supernatants of Ad5-CMV-sPDGFR $\beta$ infected COS7 cells and subjected to SDS-PAGE under nonreducing and reducing conditions (Figure 1d, left). In this analysis, the purified protein migrated as a dimer of approximately $250 \mathrm{kDa}$ under nonreducing conditions (-DTT), and as a monomer with a molecular mass around $125 \mathrm{kDa}$ under reducing conditions ( $+\mathrm{DTT})$. These results indicate that the infected cells secrete the PDGFR $\beta$-Fc fusion as a dimer, consistent with the predicted structure of the chimeric protein harboring two cysteine residues in the hinge region of the Fc portion able to form two intermolecular disulfide bonds between two sPDGFR $\beta$ molecules. Likewise, the electrophoretic mobility of the purified sT $\beta$ RII is redox-dependent (Figure 1d, right). The precise cleavage between signal sequences and mature exported soluble receptors (sPDGFR $\beta$, sT $\beta$ RII) was confirmed by amino-acid sequence analysis revealing that $\mathrm{SPDGFR} \beta$ and sT $\beta$ RII were processed at MGLPGVMPASVLRGGLL LFVLLLLGPQISQG*L (sPDGFR $\beta$ ) and MGRGLLRGL WPLHIVLWTRIAST*I (sT $\beta$ RII), respectively. The determined cleavage sites (marked by asterisks) are in agreement with the von Heijne prediction ${ }^{33}$ and are identical to the signal sequence processing sites proposed for the endogenous proteins. ${ }^{34,35}$

\section{sPDGFR $\beta$ Inhibits PDGF Signaling In Vitro}

PDGF is the most potent stimulus for HSC proliferation and induces a marked increase in cell proliferation, as measured by ${ }^{3} \mathrm{H}$-thymidine incorporation (Figure 2a, control). Preincubation with sPDGFR $\beta$ was associated with a statistically high significant inhibition of this action (Figure 2a). We next evaluated the effect of PDGF scavenging on phosphorylation of endogenous PDGFR $\beta$. Exposure of HSC to PDGF-BB resulted in tyrosine phosphorylation of a protein of $\sim 190 \mathrm{kDa}$, compatible with the size of endogenous PDGFR $\beta$ (Figure 2b). Pretreatment with sPDGFR $\beta$ prevented the phosphorylation of this band, indicating that the soluble receptor is able to interfere with early PDGF signaling. Likewise, the phosphorylation of the downstream mediators ERK1/ERK2 (p44/p42), 


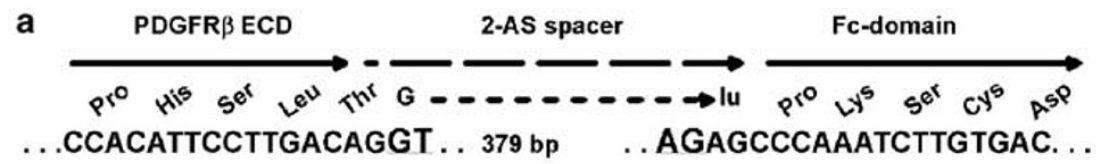

b

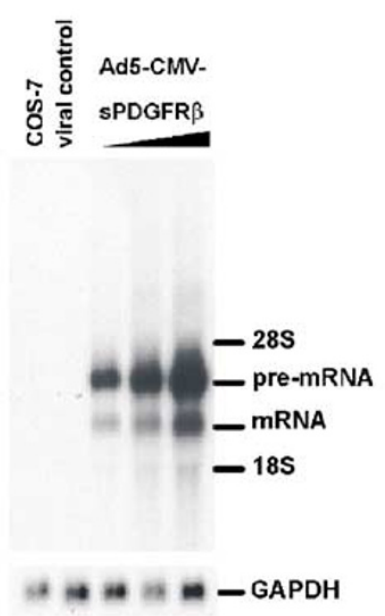

d

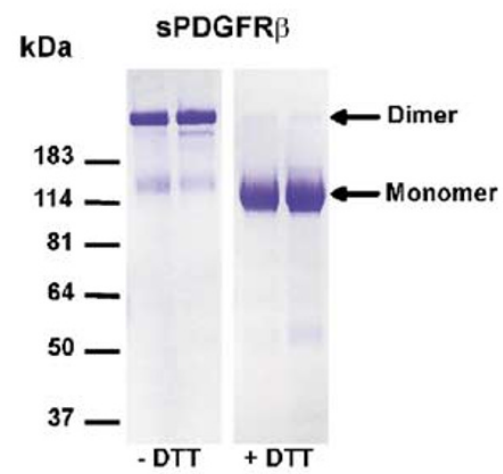

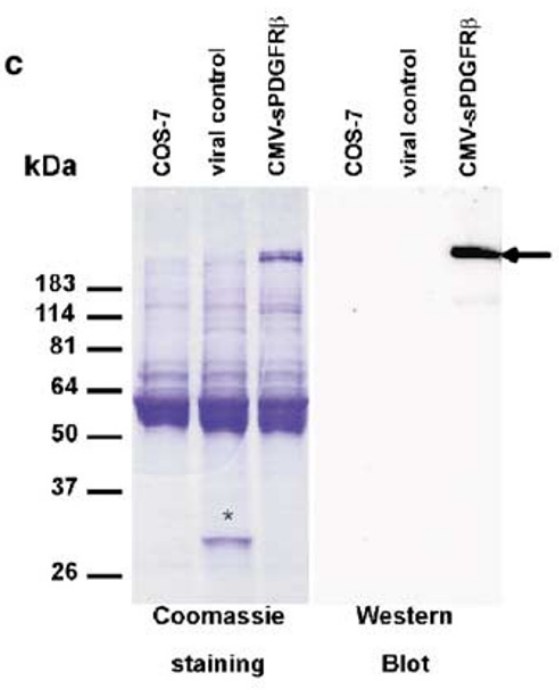

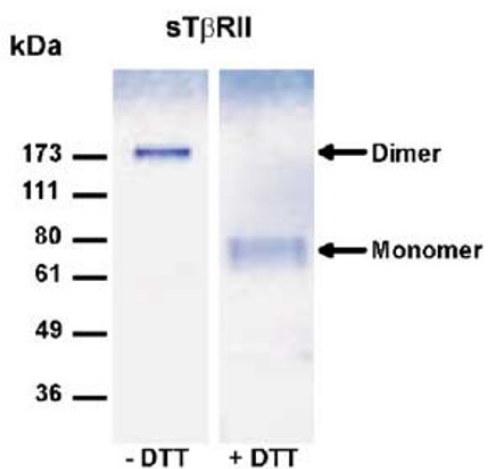

Figure 1 Construction and expression of sPDGFR $\beta$ in vitro. (a) Schematic diagram of the PDGFR $\beta$ containing the ECD of PDGF receptor

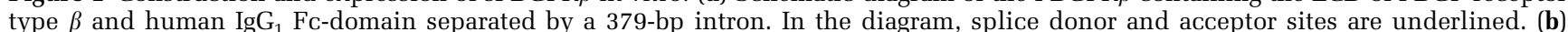
Northern blot analysis of Ad5-CMV-sPDGFR $\beta$-infected COS-7 cells. Note that the expression of respective mRNAs is dependent on viral doses. (c) SDS-PAGE and Western blot analysis of supernatants taken from COS-7 cells. Supernatants from cells infected with Ad5-CMVsPDGFR $\beta$ or Ad5-CMV-EGFP (viral control) were separated by SDS-PAGE and subjected to Western blot analysis under nonreducing conditions. The infection resulted in strong expression of sPDGFR. Also the expression of EGFP was detectable in Coomassie blue staining $\left({ }^{*}\right)$. (d) SDS-PAGE of purified soluble receptors. Both sPDGFR $\beta$ and sT $\beta$ RII show redox-dependency and migrate as dimers under nonreducing $(-\mathrm{DTT})$ conditions and as monomers under reducing conditions (+DTT).

previously shown to be an absolute requirement for triggering a proliferative response, ${ }^{9}$ was virtually abolished to background levels after pretreatment with sPDGFR $\beta$ (Figure 2c), thus again demonstrating that $\operatorname{sPDGFR} \beta$ is able to block PDGF signaling in culture-activated HSC. In contrast, incubation with PDGF was associated with the expected appearance of two bands corresponding to the phosphorylated isoforms of ERK1 (pp44) and ERK2 (pp42).

\section{Adenoviral Expression of sPDGFR $\beta$ Prevents the Progression of Hepatic Fibrosis}

Hepatic fibrosis in rats can be induced by ligature of the common $\mathrm{BD}$ for several weeks or months resulting in morphological changes in liver tissue comparable to those seen in human biliary fibrosis. $^{36-38}$ We used this experimental model of prolonged $\mathrm{BD}$ obstruction for testing the influence of sPDGFR $\beta$ on the early steps of ongoing liver fibrogenesis. We applied the adenoviral vehicle 2 days prior to setting of BDL, taken into account recent reports describing that the transduction efficiencies by adenoviral-mediated gene transfer are strongly reduced after liver injury. ${ }^{27,39,40}$ The injection with Ad5-CMV-sPDGFR $\beta$ resulted in strong hepatic expression of the transgene at the mRNA and protein levels (Figure 3 ). High amounts of sPDGFR $\beta$ were detectable $(>1 \mu \mathrm{g} / \mathrm{ml})$ in the serum at day 4 after adenoviral injection (2 days 
a

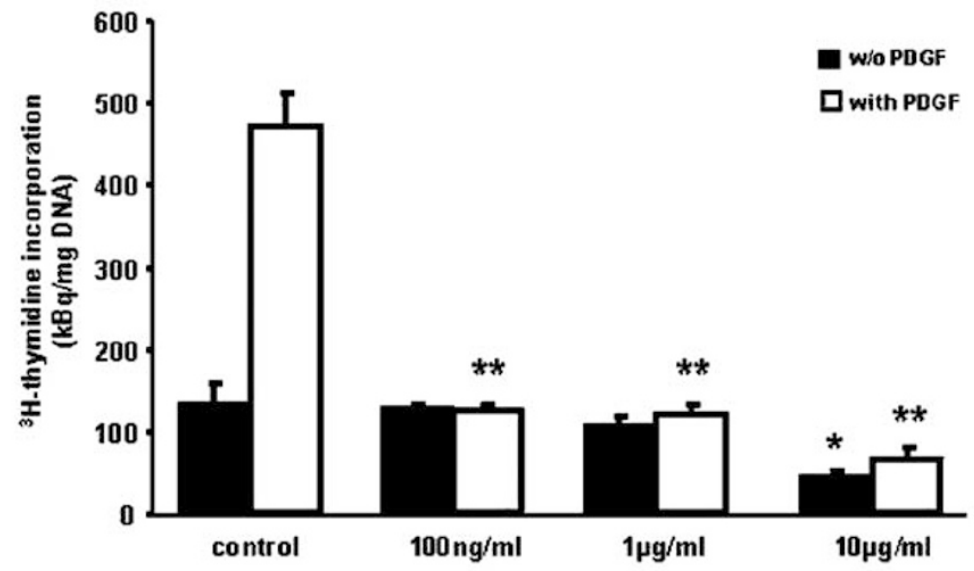

b

C

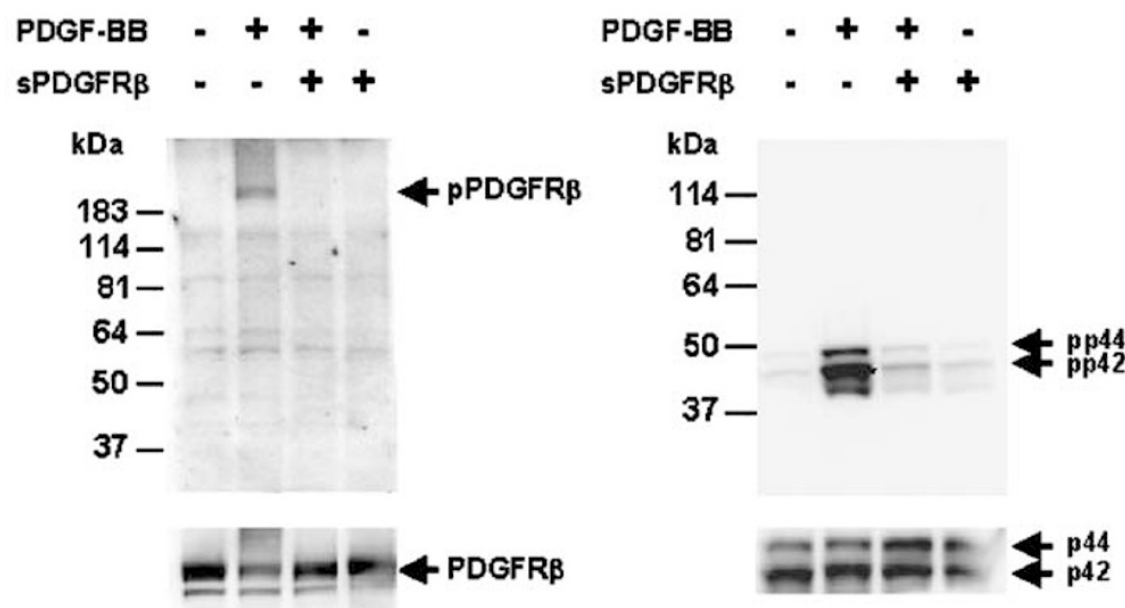

Figure 2 Functionality of sPDGFR $\beta$ in vitro. (a) Proliferation assay of culture-activated HSC. Cells were pretreated with indicated amounts of sPDGFR $\beta$ and stimulated with $20 \mathrm{ng} / \mathrm{ml}$ PDGF-BB (black bars) or left unstimulated (white bars). The experimental design was performed in triplicate and significant differences compared to control values are indicated with $P \leq 0.05\left({ }^{*}\right)$ or $P \leq 0.01\left({ }^{* *}\right)$. (b, c) Western blot analysis for detection of total (PDGFR $\beta$, p42, p44) and phosphorylated forms (pPDGFR $\beta$, pp42, pp44) of proteins involved in the PDGF signaling pathway. In the experiments, HSC were treated with indicated combinations of sPDGFR $\beta$ and PDGF-BB and protein extracts were analyzed for expression of pPDGFR $\beta$ and PDGFR $\beta$ (b), or pp44/pp42 and p44/p42 (c), respectively.

after BDL surgery) and at lower levels ( 100 ng/ml) at day 9 (7 days after BDL surgery) as assessed by Western blot analysis (Figure 3b, upper part) and ELISA (Figure $3 b$, lower part). To determine the impact of sPDGFR $\beta$ on liver fibrogenesis, the expression and deposition of collagen type I were assessed by Sirius red staining and Northern blot analysis (Figure 4). The deposition and the number of collagen fibrils was significantly decreased in rats receiving Ad5-CMV-sPDGFR $\beta$, while no reduction in the degree of fibrosis was observed in animals receiving a control adenovirus (Ad5-CMV-EGFP), indicating that the prevention was specific for Ad5CMV-sPDGFR $\beta$ (Figure 4a). The suppression of collagen type I expression was also confirmed at the transcriptional level (Figure 4b). However, we found that in this analysis the suppression of collagen type I mRNA was less pronounced but still significant.

We next examined the influence of $\operatorname{sPDGFR} \beta$ on expression of $\alpha$-smooth muscle actin ( $\alpha$-SMA), another marker of ongoing fibrogenesis and cellular activation. In animals receiving Ad5-CMVsPDGFR $\beta$, the signals obtained in $\alpha$-SMA immunostainings were markedly reduced (Figure 5), again confirming that $\mathrm{sPDGFR} \beta$ is effective in preventing progression of hepatic fibrosis.

\section{Efficacy of Purified Proteins (sPDGFR $\beta$ and sT $\beta$ RII) in Preventing Liver Fibrosis}

In hepatology research, adenoviral delivery approaches are attractive because they mainly target the expression of transgenes into the liver. However, the expressed soluble receptors are secreted and are detectable in circulating fluids (see above). Therefore, the application as purified proteins should have the same beneficial impact on hepatic fibrogenesis as the adenoviral approach. We purified large quantities of sPDGFR $\beta$ and sT $\beta$ RII from the supernatant of COS-7 cells infected by respective 
772

a

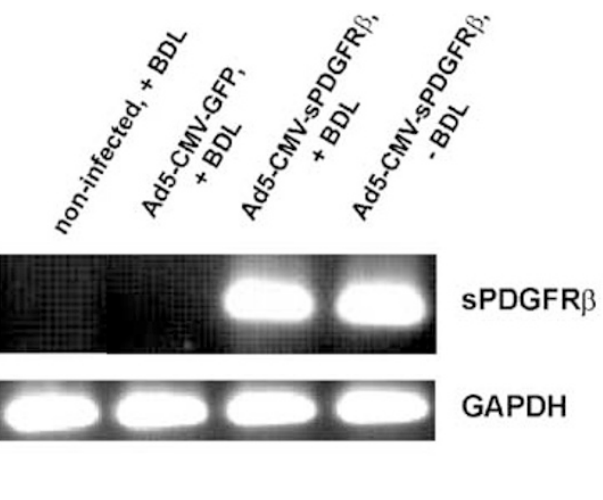

b

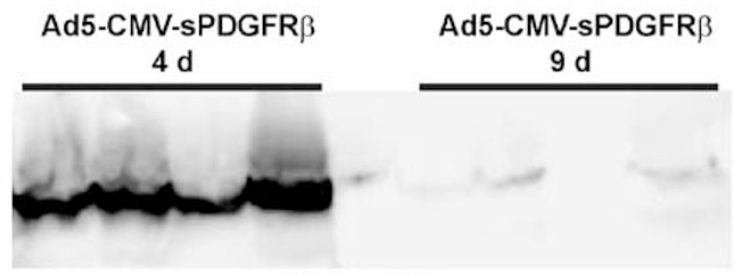

Western Blot

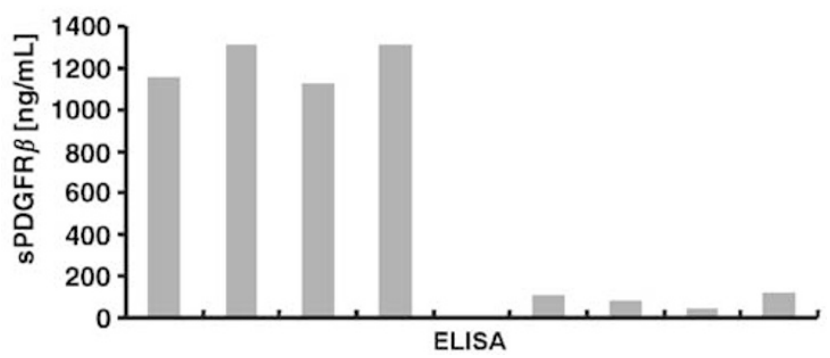

Figure 3 Expression of $\operatorname{sPDGFR} \beta$ in rats. (a) In order to detect sPDGFR $\beta$ mRNA expression in BD ligated ( + BDL) and nonligated rats ( $-\mathrm{BDL})$, total RNA was isolated 9 days after adenoviral infection (7 days after BDL surgery) from rat livers and subjected to RT-PCR. In this analysis, Ad5-CMV-EGFP-infected rats served as negative controls. To verify the integrity of individual cDNA, a $G A P D H$ specific product was amplified from each sample. (b) Western blot analysis (upper panel) and quantitative ELISA (lower panel) of serum isolated from bile duct-ligated and Ad5CMV-sPDGFR $\beta$-infected animals. Blood samples were taken at days 4 and 9 after viral infection.

adenoviruses and repeated our experiments using these purified protein fractions. As expected, the efficacy (eg collagen deposition and expression) of both soluble receptors was also seen when sPDGFR $\beta$ or sT $\beta$ RII were administered as purified proteins (Figure 6), indicating that the observed antifibrotic effects were not the result of adenoviral infection per se.

\section{Discussion}

HSC are essentially involved in the development and progression of hepatic fibrosis. Profibrogenic cytokines, such as TGF- $\beta$, trigger HSC activation that involves proliferation, enhanced production of ECM components, and a phenotypic transition towards MFB, including a loss of the characteristic retinoid- containing fat droplets. ${ }^{1}$ Consequently, local expression of a dominant-negative type II TGF- $\beta$ receptor (sT $\beta$ RII) in rat livers treated with dimethylnitrosamine resulted in attenuation of liver fibrosis in a model of persistent liver fibrosis. ${ }^{16}$ Further, the beneficial impact of sT $\beta$ RII was recently demonstrated to have an inhibitory effect on the activation of rat HSC in primary culture resulting from interruption of the TGF- $\beta$ autocrine signaling-loop. ${ }^{18}$ Among other polypeptide growth factors potentially involved in chronic liver inflammation, PDGF has shown to be the most potent mitogen for cultured HSC isolated from rat, mouse, or human liver ${ }^{3}$ reflecting the most striking molecular response of HSC to injury. Of the different possible dimeric forms of PDGF, PDGF-BB functions as the strongest stimulator of HSC growth and intracellular signaling with concurrent predominant expression of PDGFreceptor $\beta$ (or type $\beta$ ) subunits in activated HSC. ${ }^{41}$ Importantly, codistribution of PDGF with cells expressing the relative receptor subunits has been clearly demonstrated after both acute and chronic liver tissue damage, thus confirming a functional role of PDGF in the liver tissue repair process and in the development of hepatic fibrosis. ${ }^{12,5}$ For these reasons, targeting the PDGF signaling is attractive for therapeutic intervention in hepatic fibrosis. We therefore constructed a transgene, encoding the ECD of the PDGF receptor type $\beta$ fused to the IgG-Fc domain of human immunoglobulin and tested the impact of this soluble PDGF receptor $\beta$ (sPDGFR $\beta$ ) on liver fibrogenesis in vitro and in vivo. The binding of PDGF to the sPDGFR $\beta$ was confirmed in proliferation assays with PDGF-BB using cultureactivated HSC. In these studies, the preincubation of HSC with sPDGFR $\beta$ was able to reduce PDGFBB-induced mitogenic response of HSC. The phosphorylation of endogenous PDGFR $\beta$ was abrogated in response to $\mathrm{sPDGFR} \beta$. We also found that sPDGFR $\beta$ selectively inhibited the PDGF-BBinduced postreceptor phosphorylation of $\mathrm{p} 42 / \mathrm{p} 44$, consistent with previous findings indicating that autophosphorylation of $\operatorname{PDGFR} \beta$ is a prerequisite for PDGF downstream signaling via the Ras/ERKregulated kinase pathway, which is likely the signal involved in the mitogenic response to PDGF. ${ }^{42}$ These findings demonstrate that the soluble receptor is an effective means to block PDGF signaling in culture-activated HSC. In order to examine the effects of the soluble receptor on hepatic fibrosis, we used the BDL model. Previous studies have demonstrated that expression of the PDGF receptor $\beta$-subunit is increased during this experimental injury induced by biliary obstruction. ${ }^{4}$ Using this model, we showed that the adenoviral expression or direct application of $\operatorname{sPDGFR} \beta$ as purified protein significantly attenuates ongoing fibrosis as assessed by reduced expression of $\alpha$ SMA and collagen. This fits well with previous studies demonstrating that inhibitors of PDGF decrease $\alpha$-SMA immunoreactivity. ${ }^{43}$ However, 
a
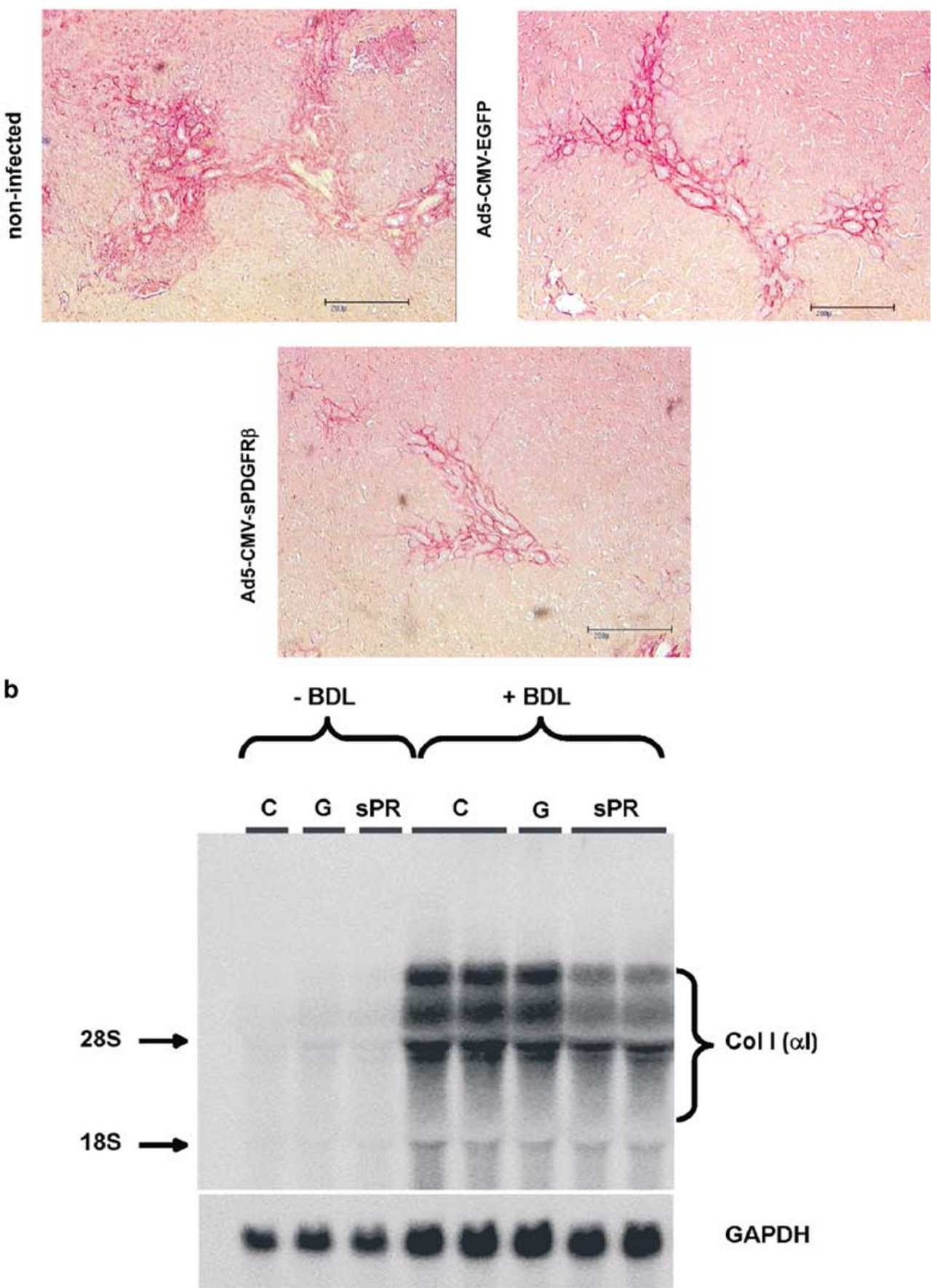

Figure 4 sPDGFR $\beta$ decreased collagen expression in BDL model of liver fibrosis. (a) Content and deposition of collagen in livers from animals subjected to BDL and injected with saline (non-infected), Ad5-CMV-EGFP (viral control), or Ad5-CMV-sPDGFR $\beta$ were analyzed by Sirius red staining. Sirius red staining results in dark red staining of collagen fibers (space bar $=200 \mu \mathrm{m}$ ). (b) Northern blot analysis of representative liver samples taken from both non-BD ligated-(-BDL) and BD ligated ( + BDL) rats after saline (c), Ad5-CMV-EGFP (G), and Ad5-CMV-sPDGFR $\beta$ (sPR) application. The sizes of $18 \mathrm{~S}$ and $28 \mathrm{~S}$ rRNAs are indicated in the left margin.

compared to sT $\beta$ RII, the PDGF antagonist exerts an overall weaker antifibrotic effect in experimentalinduced liver injury, supporting the notion that TGF- $\beta$ plays a more pivotal role in the fibroproliferative changes that occur from tissue damage. Further, the comparison of absolute expression of type I collagen mRNA and respective protein amount as assessed by Sirius red staining suggests a relatively greater reduction of collagen at the protein level after administration of $\operatorname{sPDGFR} \beta$. This discrepancy was previously described in experiments investigating the inhibition of hepatic 

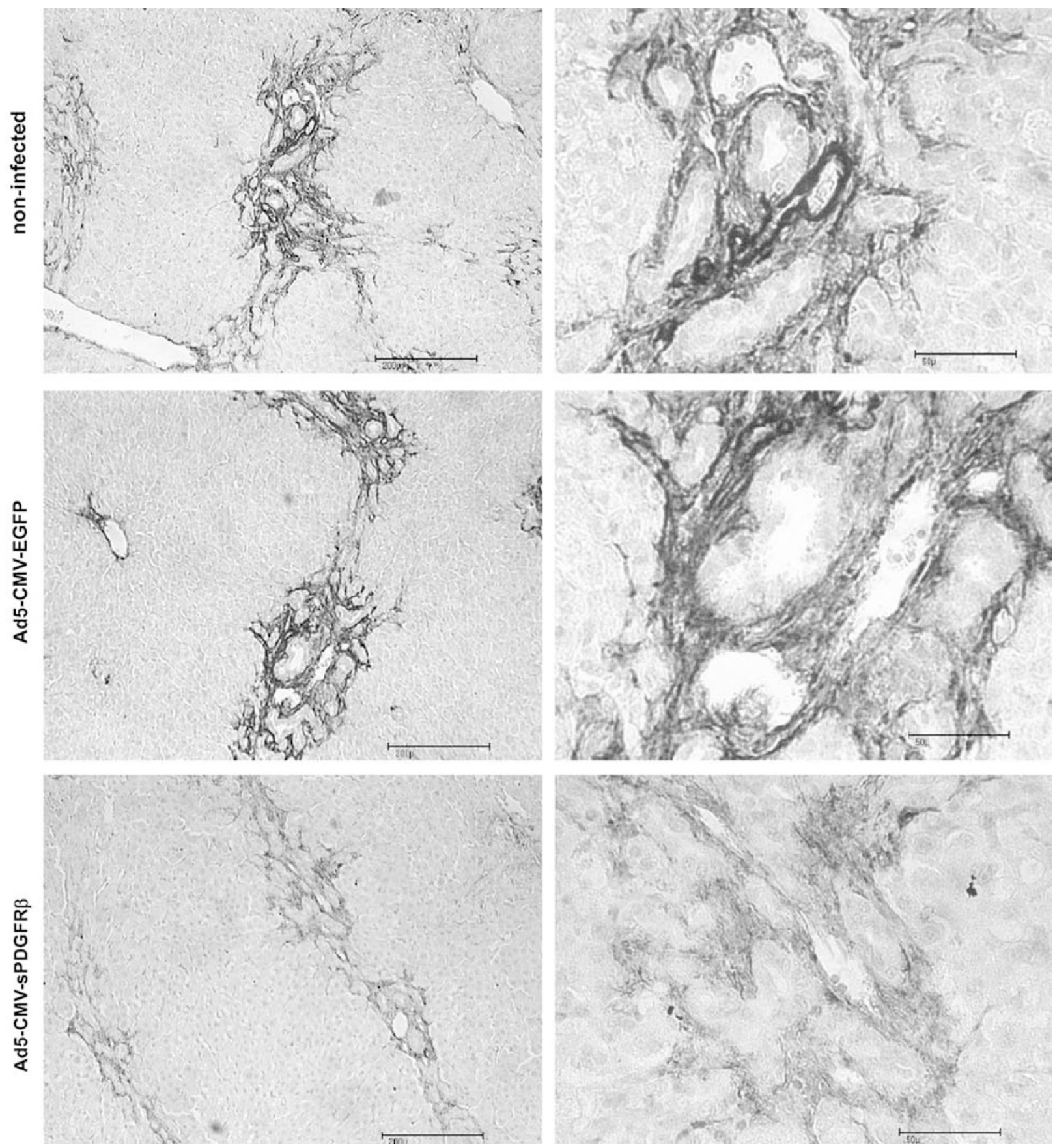

Figure 5 Reduction of smooth muscle $\alpha$-actin immunoreactivity in rat livers treated with Ad5-CMV-sPDGFR $\beta$. Immunohistological distribution of $\alpha$-SMA in representative liver sections of BD-ligated rats injected with saline (non-infected), Ad5-CMV-EGFP, or Ad5CMV-sPDGFR $\beta$. Each liver section is shown at lower (left panel; space bar $=200 \mu \mathrm{m}$ ) and higher (right panel; space bar $=50 \mu \mathrm{m}$ ) magnification.

fibrosis by $\mathrm{sT} \beta \mathrm{RII}^{30}$ and might be due to the posttranscriptional regulation of collagen expression in cultured HSC. ${ }^{44}$

We have not yet analyzed the impact of $\operatorname{sPDGFR} \beta$ with regard to chemotaxis of HSC towards BD structures that were shown to contribute to the development of periductular fibrosis in cholestatic disorders. ${ }^{45}$ Probably, the reduced fibrosis observed after treatment with $\operatorname{sPDGFR} \beta$ is not a direct consequence of interfering with the processes involved in controlling the synthesis of fibrogenic markers ( $\alpha$-SMA, collagen) per se, but may result from blockade of HSC proliferation and inhibition of chemotaxis, thereby decreasing the number of cells able to form these destructive components. This would suggest that the combined elimination of TGF- $\beta$ and PDGF could further contribute to a more effective inhibition of hepatic fibrosis. The testing of this hypothesis is a major focus of future investigations in our laboratory. 
a

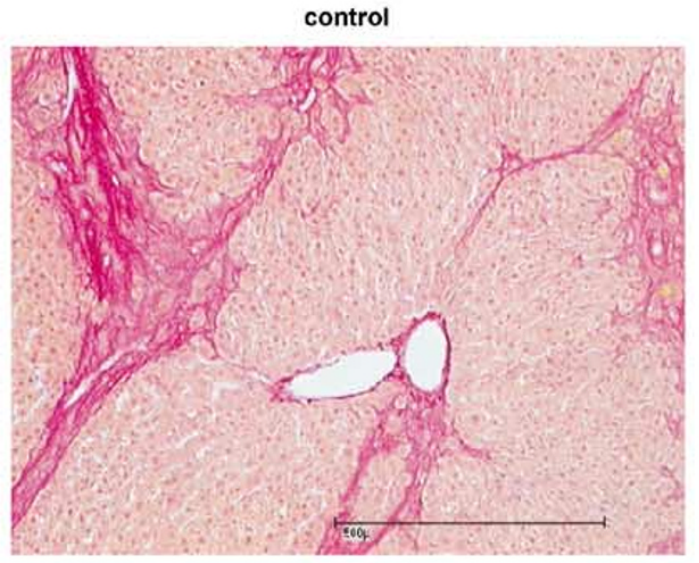

SPDGFR $\beta$

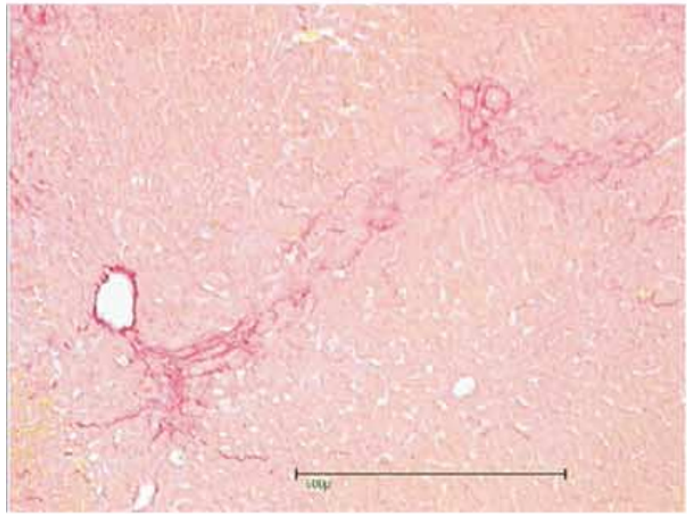

sTBR II

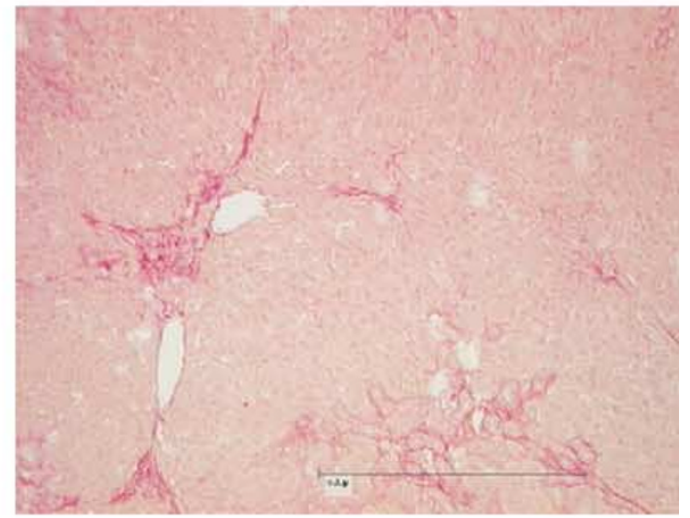

b

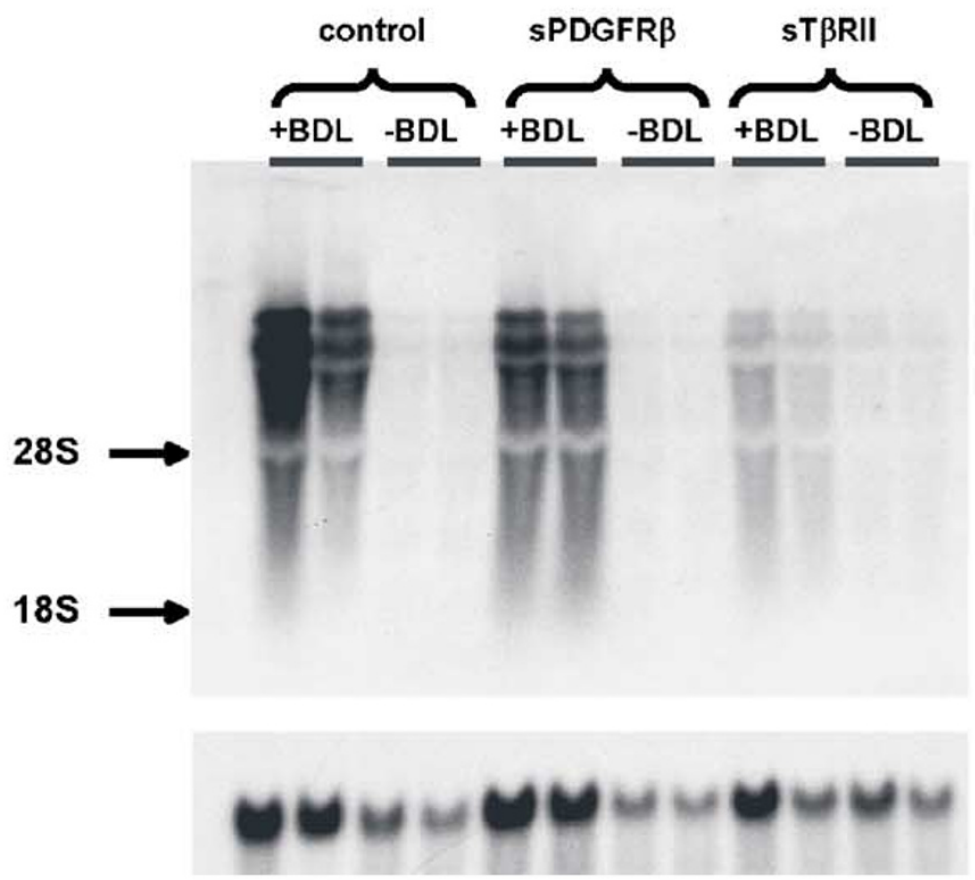

Figure 6 Administration of purified sPDGFR $\beta$ protein leads to decreased collagen expression in fibrotic rat liver. (a) Sirius red staining of liver sections from BD ligated and rats injected with saline (control), PDGFR $\beta$, or sT $\beta$ RII (space bar $=500 \mu \mathrm{m}$ ). (b) Northern blot analysis of collagen expression in livers obtained from rats with ( + BDL) and without (-BDL) receiving injection of saline (control), sPDGFR $\beta$, or sT $\beta$ RII. The sizes of $18 \mathrm{~S}$ and $28 \mathrm{~S}$ rRNAs are indicated in the left margin. 
In conclusion, the data presented herein provide evidence that sPDGFR $\beta$ is active as an antifibrogenic protein drug able to reduce the biological effects of PDGF in ongoing fibrogenesis. Therefore, the beneficial effects of this compound make it an attractive therapeutic agent for the treatment of fibrotic liver diseases and possibly other fibrotic organ lesions as well.

\section{Acknowledgements}

We thank D Vivien (Centre Cyceron, Université de Caen, Caen, France) for kindly providing pIg-sT $\beta$ RII and K Knoch (Institut für Physiologische Chemie, Technische Universität Dresden, Dresden, Germany) for sending clone pGEM-rCol $\alpha 1(\mathrm{I})$. Studies from the authorś laboratory relevant to this article have been supported by grants from the Deutsche Forschungsgemeinschaft (DFG) and from the Federal Ministry of Education and Research of Germany (BMBF, IZKF Biomat).

\section{References}

1 Friedman SL. Molecular regulation of hepatic fibrosis, an integrated cellular response to tissue injury. J Biol Chem 2000;275:2247-2250.

2 Gressner AM, Weiskirchen R, Breitkopf K, et al. Roles of TGF- $\beta$ in hepatic fibrosis. Front Biosci 2002;7: D793-D807.

3 Pinzani M. PDGF and signal transduction in hepatic stellate cells. Front Biosci 2002;7:D1720-D1726.

4 Wong L, Yamasaki G, Johnson RJ, et al. Induction of $\beta$-platelet-derived growth factor receptor in rat hepatic lipocytes during cellular activation in vivo and in culture. J Clin Invest 1994;94:1563-1569.

5 Pinzani M, Milani S, Herbst $\mathrm{H}$, et al. Expression of platelet-derived growth factor and its receptors in normal human liver and during active hepatic fibrogenesis. Am J Pathol 1996;148:785-800.

6 Cohen GB, Ren R, Baltimore D. Modular binding domain in signal transduction proteins. Cell 1995;80: 237-248.

7 Pawson T. Protein modules and signaling networks. Nature 1995;373:573-580.

8 Marshall CJ. Specificity of receptor tyrosine kinase signaling: transient vs sustained extracellular signalregulated kinase activation. Cell 1995;80:179-185.

9 Pages G, Lenormand P, L'Allemain G, et al. Mitogenactivated protein kinases p42MAPK and p44MAPK are required for fibroblast proliferation. Proc Natl Acad Sci USA 1993;90:8319-8323.

10 Marra F, Pinzani M, DeFranco R, et al. Involvement of phosphatidylinositol 3-kinase in the activation of extracellular signal-regulated kinase by PDGF in hepatic stellate cells. FEBS Lett 1995;376:141-145.

11 Marra F, Arrighi MC, Fazi M, et al. Extracellular signalregulated kinase activation differentially regulates platelet-derived growth factor's actions in hepatic stellate cells, and is induced by in vivo liver injury in the rat. Hepatology 1999;30:951-958.

12 Pinzani M, Milani S, Grappone C, et al. Expression of platelet-derived growth factor in a model of acute liver injury. Hepatology 1994;19:701-707.
13 Carloni V, Pinzani M, Giusti S, et al. Tyrosine phosphorylation of focal adhesion kinase by PDGF is dependent on Ras in human hepatic stellate cells. Hepatology 2000;31:131-140.

14 Kinnman N, Goria O, Wendum D, et al. Hepatic stellate cell proliferation is an early platelet-derived growth factor-mediated cellular event in rat cholestatic liver injury. Lab Invest 2001;81:1709-1716.

15 Iwamoto $\mathrm{H}$, Nakamuta $\mathrm{M}$, Tada $\mathrm{S}$, et al. Plateletderived growth factor receptor tyrosine kinase inhibitor AG1295 attenuates rat hepatic stellate cell growth. J Lab Clin Med 2000;135:406-412.

16 Qi Z, Atsuchi N, Ooshima A, et al. Blockade of type $\beta$ transforming growth factor signaling prevents liver fibrosis and dysfunction in the rat. Proc Natl Acad Sci USA 1999;96:2345-2349.

17 George J, Roulot D, Koteliansky VE, et al. In vivo inhibition of rat stellate cell activation by soluble transforming growth factor $\beta$ type II receptor: a potential new therapy for hepatic fibrosis. Proc Natl Acad Sci USA 1999;96:12719-12724.

18 Cui X, Shimizu I, Lu G, et al. Inhibitory effect of a soluble transforming growth factor $\beta$ type II receptor on the activation of rat hepatic stellate cells in primary culture. J Hepatol 2003;39:731-737.

19 Seglen PO. Preparation of isolated rat liver cells. Meth Cell Biol 1987;8:29-83.

20 Weiskirchen R, Moser M, Weiskirchen S, et al. LIMdomain protein cysteine- and glycine-rich protein 2 (CRP2) is a novel marker of hepatic stellate cells and binding partner of the protein inhibitor of activated STAT1. Biochem J 2001;359:485-496.

21 Weiskirchen R, Kneifel J, Weiskirchen S, et al. Comparative evaluation of gene delivery devices in primary cultures of rat hepatic stellate cells and rat myofibroblasts. BMC Cell Biol 2000;1:4.

22 Komesli S, Vivien D, Dutartre P. Chimeric extracellular domain type II transforming growth factor (TGF)- $\beta$ receptor fused to the $\mathrm{F}_{\mathrm{C}}$ region of human immunoglobulin as a TGF- $\beta$ antagonist. Eur J Biochem 1998;254: 505-513.

23 Bett AJ, Haddara W, Prevec L, et al. An efficient and flexible system for construction of adenovirus vectors with insertions or deletions in early regions 1 and 3 . Proc Natl Acad Sci USA 1994;91:8802-8806.

24 McGrory WJ, Bautista DS, Graham FL. A simple technique for the rescue of early region I mutations into infectious human adenovirus type 5. Virology 1988;163:614-617.

25 Fehrenbach H, Weiskirchen R, Kasper M, et al. Upregulated expression of the receptor for advanced glycation end products in cultured rat hepatic stellate cells during transdifferentiation to myofibroblasts. Hepatology 2001;34:943-952.

26 Arias M, Lahme B, Van de Leur E, et al. Adenoviral delivery of an antisense RNA complementary to the $3^{\prime}$ coding sequence of transforming growth factor- $\beta 1$ inhibits fibrogenic activities of hepatic stellate cells. Cell Growth Differ 2002;13:265-273.

27 Herrmann J, Abriss B, van de Leur E, et al. Comparative analysis of adenoviral transgene delivery via tail or portal vein into rat liver. Arch Virol 2004;149. doi: 10.1007/S00705-004-0300-4.

28 Herrmann J, Arias M, Van de Leur E, et al. CSRP2, TIMP-1 and SM22 $\alpha$ promoter fragments direct hepatic stellate cell-specific transgene expression in vitro, but not in vivo. Liver Int 2004;24:69-79. 
29 Zerbe O, Gressner AM. Proliferation of fat-storing cells is stimulated by secretions of Kupffer cells from normal and injured liver. Exp Mol Pathol 1988;49: 87-101.

30 Yata Y, Gotwals P, Koteliansky V, et al. Dose-dependent inhibition of hepatic fibrosis in mice by a TGF- $\beta$ soluble receptor: implications for antifibrotic therapy. Hepatology 2002;35:1022-1030.

31 Lopez-De Leon A, Rojkind M. A simple micromethod for collagen and total protein determination in formalin-fixed paraffin-embedded sections. J Histochem Cytochem 1985;33:737-743.

32 Weiskirchen R, Abriss B, Arias M, et al. Experimental approaches to antifibrotic strategies using gene transfer. In: Gressner AM, Heinrich PC, Matern S (eds). Progress in Gastroenterol and Hepatology: Cytokines in Liver Injury and Repair. Kluwer Academic Publishers: Dordrecht, The Netherlands, 2002, pp 335-353.

33 von Heijne G. Patterns of amino acids near signalsequence cleavage sites. Eur J Biochem 1983;133:17-21.

34 Lin HY, Wang XF, Ng-Eaton E, et al. Expression cloning of the TGF- $\beta$ type II receptor, a functional transmembrane serine/threonine kinase. Cell 1992;68:775-785.

35 Claesson-Welsh L, Eriksson A, Moren A, et al. cDNA cloning and expression of a human platelet-derived growth factor (PDGF) receptor specific for B-chaincontaining PDGF molecules. Mol Cell Biol 1988;8: 3476-3486.

36 Accatino L, Contreras A, Fernandez S, et al. The effect of complete biliary obstruction on bile flow and bile acid excretion: postcholestatic choleresis in the rat. J Lab Clin Med 1979;93:706-717.

37 Kountouras J, Billing BH, Scheuer PJ. Prolonged bile duct obstruction: a new experimental model for cirrhosis in the rat. Br J Exp Pathol 1984;65:305-311.
38 Arias M, Sauer-Lehnen S, Treptau J, et al. Adenoviral expression of a transforming growth factor- $\beta 1$ antisense mRNA is effective in preventing liver fibrosis in bile-duct ligated rats. BMC Gastroenterology 2003; $3: 29$.

$39 \mathrm{Yu}$ Q, Shao R, Qian HS, et al. Gene transfer of the neuronal NO synthase isoform to cirrhotic rat liver ameliorates portal hypertension. J Clin Invest 2000; 105:741-748.

40 Yu Q, Que LG, Rockey DC. Adenovirus-mediated gene transfer to nonparenchymal cells in normal and injured liver. Am J Physiol Gastrointest Liver Physiol 2002;282:G565-G572.

41 Pinzani M, Gentilizi A, Caligiuri A, et al. Transforming growth factor- $\beta 1$ regulates platelet-derived growth factor receptor $\beta$ subunit in human liver fat-storing cells. Hepatology 1995;21:232-239.

42 Pinzani M, Marra F, Caligiuri A, et al. Inhibition by pentoxifylline of extracellular signal-regulated kinase activation by platelet-derived growth factor in hepatic stellate cells. Br J Pharmacol 1996;119: 1117-1124.

43 Kinnman N, Francoz C, Barbu V, et al. The myofibroblastic conversion of peribiliary fibrogenic cells distinct from hepatic stellate cells is stimulated by platelet-derived growth factor during liver fibrogenesis. Lab Invest 2003;83:163-173.

44 Stefanovic B, Hellerbrand C, Holcik M, et al. Posttranscriptional regulation of collagen $\alpha 1(\mathrm{I})$ mRNA in hepatic stellate cells. Mol Cell Biol 1997;17: 5201-5209.

45 Kinnman N, Hultcrantz R, Barbu V, et al. PDGFmediated chemoattraction of hepatic stellate cells by bile duct segments in cholestatic liver injury. Lab Invest 2000;80:697-707. 